\title{
EL EVENTO DESENCADENANTE DE LA GARANTÍA DE LUCRO CESANTE Y EL TÉRMINO DE LA PRESCRIPCIÓN ORDINARIA*
}

\section{EVENT TRIGGERING BUSINESS INTERRUPTION INSURANCE AND THE ORDINARY DELAY TO POLICY LAPSATION}

Felipe Tabares Cortés**

Fecha de recepción: 9 de diciembre de 2016 Fecha de Aceptación: 15 de diciembre de 2016

Disponible en línea: 30 de diciembre de 2016

\section{Para Citar este artículo/To cite this article}

Tabares Cortés, Felipe, El evento desencadenante de la garantía de lucro cesante y el termino de la prescripción ordinaria, 45 Rev.IberoLatinoam.Seguros, 151-184 (2016). http://dx.doi.org/10.11144/Javeriana. ris45.edg1

doi:10.11144/Javeriana.ris45.edg1

* Reseña crítica y doctrinal sobre la reciente jurisprudencia de la Corte Suprema de Justicia sobre la garantía de lucro cesante.

** Abogado de la Universidad de Caldas, especialista en Derecho Médico de la Universidad del Rosario, Maestría en Derecho de Seguros de l'Université Lyon III Jean Moulin, Preparación del Centro Regional de Formación de Abogados de l'Université Paris II Panthéon-Assas, Summer Academy on International Investment Law and Dispute Settlement, Kuala Lumpur Regional Centre for Arbitration, Malasia. Contacto: felipetaba@gmail.com www. fr.linkedin.com/in/felipetabarescortes 


\section{RESUMEN}

La Sentencia SC 7814-2016 de 15 de junio de 2016, la Sala de Casación Civil de la Corte Suprema de Justicia define el tema de la cobertura de lucro cesante del seguro de incendio y fija la noción que en derecho colombiano le es dable al siniestro en este tipo de garantías. El presente artículo busca exponer los argumentos de la Corte Suprema en la sentencia de 15 de junio de 2016 dentro del discurso doctrinal de derecho de seguros colombiano e integrarlos en el debate internacional para tener elementos de prospección sobre la actualización y perfectibilidad del sistema jurídico colombiano. Es por ello que en primera medida será mencionado el debate jurídico alrededor de la garantía de lucro cesante (I) para luego referir en concreto cómo resolvió la Corte la pregunta sobre la prescripción en la garantía de lucro cesante (II).

Palabras clave: seguro de lucro cesante; forma inglesa; definición de siniestro; prescripción; derecho de daños; consolidación; contenido obligacional; exigibilidad. 


\begin{abstract}
The Civil Chamber of Colombia's Supreme Court in Decision SC 7814-2016 of 15th June 2016 reversed a Second Degree Decision referred to business interruption cover in fire insurance. In this Decision, the Supreme Court held the notion that in Colombian law exist about loss in business interruption insurance. This article describes the position of the Supreme Court in the local discussion of insurance law and tries to align the Court's arguments in the international academic dialogue. Our query tended to find prospective elements to improve the Colombian insurance law system. Hence, we will develop in a first moment the academic discussion about the business interruption insurance (I) to later describe the Supreme Court's arguments concerning the question about the period of policy lapsation (II).
\end{abstract}

Key words: business interruption insurance; gross profit insurance; notion of loss; lapse of policy; property insurance; right's activation; insurer's duty to pay.

\title{
SUMARIO
}

I. El debate jurídico alrededor de la garantía de lucro cesante. A. El debate judicial que originó la Sentencia. 1. El trámite de primera y segunda instancia. 2. Los argumentos de las partes durante el recurso de casación. B. Clasificación jurídica del seguro de lucro cesante. 1. Naturaleza de la garantía de lucro cesante en forma inglesa. 2. Operación de la cobertura de lucro cesante en forma inglesa. II. La prescripción de la garantía de lucro cesante. A. La prescripción en el derecho de daños. 1. El elemento desencadenante de la garantía de lucro cesante. 2. Consolidación y exigibilidad de la obligación del asegurador. B. La configuración del precedente judicial. 1. El precedente sentado por la Corte y los elementos de autoridad utilizados. 2. La configuración del siniestro en la garantía de lucro cesante en Common Law. 


\section{INTRODUCCIÓN}

Un país en crecimiento económico debe concentrarse no solo en la preservación de los activos empresariales, sino también en los márgenes de productividad. La garantía de lucro cesante ha sido una herramienta indispensable durante el proceso de consolidación de los sectores económicos de los países industrializados. Si bien Colombia se encuentra en un periodo de expansión económica, dicha ventaja está siempre amenazada por el alto nivel de riesgo que representa un país como el nuestro: catástrofes naturales, afectación de suministros por falla en la infraestructura energética o de transporte y delincuencia. Es por esto que la garantía de lucro cesante se erige como un parte de tranquilidad para el sector empresarial ${ }^{1} \mathrm{y}$ como una manera de afianzar el empleo y el uso de los recursos en nuestro país.

\section{EL DEBATE JURÍDICO ALREDEDOR DE LA GARANTÍA DE LUCRO CESANTE}

Llamada por algunos como el "seguro de vida de la empresa" 2 esta garantía es considerablemente comercializada en el país lo que demuestra su capacidad para mantener la actividad económica del comerciante que afronta un siniestro que interrumpió el curso de sus negocios. La Sentencia SC 7814-2016 de 15 de junio de 2016 de la Sala de Casación Civil de la Corte Suprema de Justicia analiza esta garantía, recuerda sus principios rectores, menciona su forma de operación a nivel nacional y en otras jurisdicciones y decide un punto de derecho hasta este momento inacabado por la jurisprudencia nacional. Es por esto que se trata de una sentencia hito ${ }^{3}$ puesto que tiene sin duda gran importancia doctrinal y establece un elemento estructural en el funcionamiento de algunos seguros patrimoniales de nuestro país. El debate jurídico comenzó evidentemente por el trámite judicial (A) lo que exigió consecuentemente establecer cuál es la clasificación propia de la garantía de lucro cesante (B).

1 Frente a los seguros que cubren los activos empresariales afirmó la Corte Constitucional en Sentencia C385/08 en el análisis de Decreto 624 de 1989: "El interés del Estado en que las sociedades se capitalicen y trabajen con sus propios recursos; que el beneficiario recupere su patrimonio asegurado y perdido; que, mediante la reinversión en activos iguales o similares, se asegure la continuidad de la actividad económica del sujeto".

2 Kullman, J.; Habib-Deloncle L. et al. (2016) Lamy Assurances, Lamyline, Assurances dommages, Assurances des biens de l'entreprise, Aspect prospectif de l'assurance pertes d'exploitation, No. 1739.

3 López Medina, D. E. (2004) El derecho de los jueces. Legis, Universidad de los Andes, Bogotá, p. 161. 


\section{A. El debate judicial que originó la Sentencia}

Una sociedad de comercialización internacional adquirió un contrato de seguro de incendio en momentos previos a que una conflagración consumiera los bienes objeto de protección. La empresa aseguradora asumió el costo del daño emergente sufrido por la empresa, pero para cubrir el lucro cesante solicitó al asegurado una serie de documentos. El asegurado cumplió con dicha exigencia, pero a pesar de ello, pasado un año el asegurador no se había pronunciado frente al siniestro. El asegurado interpuso entonces una demanda en contra de la aseguradora la cual fue contestada afirmando que su silencio estuvo justificado en la falta de demostración del evento asegurado, además de haber formulado la excepción de prescripción. El conflicto así presentado fue desatado en los trámites de primera y de segunda instancia (1) pero fue reabierto con los argumentos de las partes durante el trámite de casación (2).

\section{El trámite de primera y segunda instancia}

La primera instancia, el Juez de Circuito de Medellín, constató la existencia del siniestro pero declaró fundada la excepción de prescripción.

Por su parte, el Tribunal Superior encontró que la cobertura se extendía al tiempo de interrupción del negocio asegurado cuyo monto se limita a la pérdida de utilidad causada por la disminución de ingresos y el aumento de gastos de funcionamiento.

Sin embargo, el Tribunal confirmó la excepción declarada a favor del asegurador precisando que el término de prescripción comenzó desde la ocurrencia del incendio y no como lo afirmaba el actor que debía contarse desde la entrega por el asegurado del ejercicio contable necesario para establecer el ajuste de pérdidas.

\section{Los argumentos de las partes durante el trámite de casación}

La demandante recurrió extraordinariamente denunciando que el seguro de lucro cesante, como garantía de la expectativa de aumento patrimonial en el futuro, ampara las utilidades frustradas y los gastos fijos de funcionamiento durante un periodo determinado y no la mera posibilidad de proseguir la actividad empresarial interrumpida. 
Afirmó que para cuantificar el valor a indemnizar era necesario realizar acentuadas labores técnicas para determinar el aumento esperado durante el tiempo de interrupción de la empresa. Tratándose entonces de una situación duradera en el tiempo y no de inmediata realización, el término de la prescripción no podía contarse desde el momento de conocimiento de la circunstancia que originó el siniestro, sino de la articulación sucesiva de tres factores, como son, el agotamiento del período de indemnización, el restablecimiento de la actividad mercantil y la elaboración del informe final de ajuste. Solo una vez ocurridos estos hechos, en palabras del recurrente, el lapso prescriptivo echa a andar pues solo desde ese momento el interesado tiene posibilidad de hacer valer el derecho.

La aseguradora, opositora en el tramite extraordinario, argumentó por el contrario que el hecho base de la acción debe coincidir con el del siniestro so pena de desconocer los términos del contrato de seguro. Manifestó que si bien el periodo de indemnización pactado es subsiguiente a la fecha del siniestro, lo cual corresponde a una técnica de limitación del valor asegurado, ello en modo alguno modifica la forma de computar el término de prescripción el cual se sujeta a lo pactado en el contrato.

\section{B. Clasificación jurídica del seguro de lucro cesante}

Preceptúa la Sala Civil de la Corte Suprema de Justicia de Colombia que la garantía de lucro cesante en forma inglesa se caracteriza por la protección de la actividad económica del asegurado durante el periodo de paralización de la propiedad, de la empresa o del elemento generador de la renta o utilidad ${ }^{4}$.

Recordemos que la forma inglesa (gross profit) busca la garantía del beneficio producto del ingreso bruto menos los gastos durante un periodo predeterminado ${ }^{5}$, mientras que la forma americana (gross earnings) busca garantizar la pérdida sufrida únicamente durante la reconstrucción del

4 Página 15 párrafo $3 o$ de la Sentencia.

5 Gross earnings coverage and gross profits insurance, Glossary of Insurance \& Risk Management Terms, International Risk Management Institute, 2016, recuperado el 8 de noviembre de 2016 en: https://www.irmi.com/online/insurance-glossary/terms/g/gross-profits-insurance.aspx 
bien objeto del seguro ${ }^{6}$, cubriendo la capacidad de rentabilidad aun si la actividad económica continua interrumpida.

Así, para establecer una clasificación jurídica se exige describir en primer orden la naturaleza de la garantía (1) lo cual permite después apreciar el modo en que opera la cobertura de lucro cesante en forma inglesa (2).

\section{Naturaleza de la garantia de lucro cesante en forma inglesa}

El Código de Comercio, en su artículo 1083, establece que tiene interés asegurable toda persona cuyo patrimonio pueda resultar afectado por la realización del siniestro. Así, cuando un patrimonio puede verse afectado se encuentra en una relación o vínculo concreto con un bien determinado ${ }^{7}$ que puede ser cubierto con un contrato de seguro. El lucro cesante se define en forma general como aquella lesión patrimonial consistente en la pérdida de una suma que en condiciones normales se esperaba ganar ${ }^{8}$. Es por ello que el seguro de lucro cesante se constituye en una garantía específica a la afectación que puede causársele al patrimonio por la desaparición del bien cubierto con el contrato y que generaba utilidad.

Tradicionalmente definida como el amparo que busca reemplazar a la empresa en la situación que hubiera tenido en ausencia de siniestro, esta garantía se explica a través de cuatro elementos conceptuales ${ }^{9}$ :

a. Es originada por la realización de un evento garantizado en el contrato de seguro;

6 Ibid.

7 Alzate Ossa, M. (2013). Los Incoterms, El Contrato de Seguro y la compraventa Internacional de mercaderías: La transferencia del dominio y del riesgo en el contrato de Compraventa internacional y Los incoterms, y su relación con El interés asegurable y la cobertura En el contrato de seguro. Revista Principia Iuris nro. 19. Universidad Santo Tomás de Aquino.

8 Moreno, D. G. (2016). Tendencias del lucro cesante en el régimen de responsabilidad extracontractual de Estado en el derecho colombiano a partir de la Constitución de 1991. Academia \& Derecho, (10), 157-184.

9 Kullman, J.; Habib-Deloncle L. et al. (2016) Lamy Assurances, Lamyline, Assurances dommages, Assurances des biens de l'entreprise, No. 1732. 
b. Es otorgada por un tiempo determinado denominado periodo de indemnidad;

c. Es liquidada a partir de la pérdida financiera sufrida por la empresa;

d. Es adicionada con los gastos necesarios a la limitación de las consecuencias del siniestro.

Estos cuatro elementos se articulan de manera transversal para perfilar la naturaleza de la garantía (i), los riesgos cubiertos (ii), la forma en que se realiza la declaración de riesgos por el asegurado (iii) y finalmente en las particularidades de la comercialización del amparo (iv).

I. El amparo es complementario a otra cobertura de un seguro de daños y por ello debe hacerse distinción frente al seguro que cubre los deterioros o la destrucción directa de las cosas aseguradas ${ }^{10}$. El amparo de lucro cesante está relacionado indirectamente ${ }^{11}$ con los bienes objeto de cobertura pero hace parte de una garantía independiente ${ }^{12}$ que generalmente es complementaria a otro contrato ${ }^{13}$ y que abarca los beneficios no realizados ${ }^{14}$ así como los gastos generales y constantes de la empresa ${ }^{15}$. Es por ello que se dice que la indemnidad de lucro cesante está necesariamente aparejada al desempeño de la empresa, el cual determinará en definitiva los montos a otorgar al asegurado ${ }^{16}$.

10 La doctrina cita como ejemplo de esta distinción el hecho que el seguro de eventos y espectáculos cubre el lucro cesante que surge del incendio del estadio que imposibilita la realización del concierto previsto, pero el daño del estadio como tal hace parte de otra garantía que el es ajena y cuyo asegurado es el propietario: Vadja, P. (2010) De la fête de club aux jeux olympiques... check-list de l'assurance d'un événement sportif. Jurisport, Dalloz, 2010, nº6, p.31.

11 Pero se ha considerado que hay una relación íntima en la medida en que es condición para el surgimiento de la obligación de indemnizar el lucro cesante la cobertura de daño material: Laudo Arbitral Colombiana de Incubación S.A.-Incubacol-contra Seguros Colpatria S.A. 31 de Marzo de 2.009 (Colombia) Pdte Antonio De Irisarri Restrepo, párrafos $2^{\circ}$ a $4^{\circ}$ página 41.

12 Esta clasificación es consecuente con la naturaleza que desde el derecho de la responsabilidad civil se le atribuye al lucro cesante, o también denominado como perjuicios consecuenciales: Prado Simons, A. M. (2014) Fundamentos del Seguro de Responsabilidad Civil. Revista Ibero-Latinoamericana de Seguros, Bogotá (Colombia), 41(23): 119-139, julio-diciembre de 2014.

13 Estas garantías complementarias funcionan de manera independiente y no están regidas por las mismas reglas como lo recordó la Sentencia No. 28278 de la Sección Tercera del Consejo de Estado de febrero 12 de 2015, C. P. Carlos Alberto Zambrano, pagina 20 parrafo 1.

14 Otros han clasificado dichos perjuicios en los riesgos consecuenciales propiamente dichos, que se diferencian de aquellos contingentes en la magnitud de la interrupción: Cárdenas, M. B. (2010). Los seguros en Colombia. Apuntes Contables, Universidad Externado (12).

15 Página 19 párrafo 20 de la Sentencia comentada de 15 de junio de 2016 de la Corte Suprema.

16 Kullman, J.; Habib-Deloncle L. et al. (2016) Lamy Assurances, Lamyline, Assurances dommages, Assurances des biens de l'entreprise, No. 1732. 
Esta característica de accesoriedad se debe a que, en la práctica, se hace necesaria la intervención de un mismo asegurador para ambos riesgos (los bienes de la empresa y sus utilidades) puesto que cualquier inconveniente con el funcionamiento de la primera garantía afectará forzosamente el desarrollo de la segunda, verbigracia, cuando la reconstrucción del local no cumplió con los requerimientos de tiempo o de calidad, la retoma de la actividad va a ser perturbada ${ }^{17}$.

El propósito del amparo de lucro cesante es pues disminuir las pérdidas y el impacto que causa la paralización de una empresa por la ocurrencia de un riesgo determinado ${ }^{18}$. Así, el asegurador tendrá en cuenta el tiempo para proveerse de materia prima, de los costos y de las dificultades logísticas de la reposición de maquinaria o de la reconstrucción de la infraestructura física ${ }^{19}$. El amparo cubre de esta manera el beneficio neto, los gastos fijos y extraordinarios de producción, de modo que se perciba el ingreso necesario para el mantenimiento de la empresa.

La garantía de lucro cesante es un seguro de daños de cuya esfera se proscribe el enriquecimiento injusto ${ }^{20}$. Así, en virtud del principio indemnizatorio del artículo 1088 del Código de Comercio ${ }^{21}$ este amparo debe ser objeto de un acuerdo expreso entre las partes a menos que se trate de la garantía única en la contratación estata ${ }^{22} \mathrm{o}$ de aquellos contratos en los cuales la garantía está subsumida en el contrato ${ }^{23}$. Como se mencionó,

17 Kullman, J.; Habib-Deloncle L. et al. (2016) Lamy Assurances, Lamyline, Assurances dommages, Assurances des biens de l'entreprise, No. 1733.

18 JurisClasseur Responsabilite civile et Assurances (2003). Fasc. 521: Assurances Terrestres. Assurances relatives aux biens, Pertes d'exploitation.

19 Página 20 párrafo 2o de la Sentencia comentada de 15 de junio de 2016 de la Corte Suprema.

20 Restrepo Rodríguez, T. (2011) El reembolso de los costos de prevención en el seguro de responsabilidad civil en el derecho inglés. Revista de Derecho Privado, no 20, enero-junio de 2011, pp . 399 a 435.

21 Esta exigencia del pacto expreso para el lucro cesante se encuentra además en el derecho francés: Tamayo Jaramillo, J.; Ossa Gómez, D. (2015) La responsabilidad civil y los seguros en la construcción de inmuebles: una aproximación comparativa entre el derecho colombiano y francés. Revista IberoLatinoamericana de Seguros, Bogotá (Colombia), 43(24): 171-191, julio-diciembre de 2015.

22 Según el artículo 137 del Decreto 1510 de 2013, en el amparo de responsabilidad extracontractual de la garantía única, los perjuicios materiales comprenden tanto el daño emergente como el lucro cesante: Narváez Bonnet, J. E. (2014) Régimen vigente de la garantía única en la contratación estatal en Colombia. Revista Ibero-Latinoamericana de Seguros, Bogotá (Colombia), 40(23): 79-130, enerojunio de 2014.

23 Recientemente se estableció como ratio decidendi en la Sentencia No. 28278 de la Sección Tercera del Consejo de Estado de febrero 12 de 2015, C. P. Carlos Alberto Zambrano, en la página 22 párrafo 3o, que dependiendo de la naturaleza del riesgo amparado, la anterior regla puede ser exceptuada, como, por ejemplo, cuando el seguro de cumplimiento cubre el pago de los arrendamientos de un inmueble, caso en el cual, el lucro cesante es precisamente el perjuicio indemnizable. 
este amparo se centra en el restablecimiento de la actividad económica de la empresa en la situación financiera que hubiera sido en ausencia del siniestro ${ }^{24}$. Los resultados de la empresa del periodo inmediatamente anterior son entonces esenciales ${ }^{25}$, así como la noción de margen bruto que sirve de base de cálculo de la prestación debida por el asegurador ${ }^{26}$.

Si de un lado, el asegurador tiene un rol esencialmente indemnizatorio, el asegurado tiene por su parte un rol activo puesto que tiene que tomar las medidas necesarias para contener la disminución de la cifra de negocios ${ }^{27}$ como si se tratara de una persona no asegurada ${ }^{28}$ y por ello debe reiniciar en lo posible ${ }^{29} \mathrm{y}$ de forma expedita aquellas actividades empresariales que no fueron afectadas por el siniestro ${ }^{30}$. Así, ocurrido un siniestro la empresa debe poner en ejecución todas las medidas tendientes a limitar las consecuencias del suceso, pero el análisis del comportamiento del asegurado dependerá del grado de afectación que le causó el accidente, según se trate de un incendio, una catástrofe natural, una disfunción en un equipo, o un daño de carácter eléctrico o electrónico ${ }^{31}$.

II. El objeto de la garantía es el remanente del flujo de productos y de las cargas de la empresa durante un periodo de tiempo establecido en el contrato. Aunque complementaria, la garantía tiene un cuerpo de reglas propias porque su operación exige un análisis independiente en razón del funcionamiento particular del riesgo relativo a las finanzas

24 Para la conceptualización que en derecho colombiano y francés se le otorga al lucro cesante: Henao, J. C. (2007) El Daño. Universidad Externado, Bogotá, p. 228.

25 JurisClasseur Responsabilite civile et Assurances, 2003. Fasc. 521 : Assurances Terrestres. Assurances relatives aux biens, Pertes d'exploitation.

26 Sin embargo en otras jurisdicciones se ha establecido que los jueces pueden utilizar u ordenar utilizar otras herramientas de cálculo según los términos del contrato: Cass. 1re civ., 7 nov. 2000, n 97 22.294, n 1644 (Francia) citado en: JurisClasseur Responsabilite civile et Assurances, 2003. Fasc. 521 : Assurances Terrestres. Assurances relatives aux biens, Pertes d'exploitation.

27 Esta carga proviene directamente de las obligaciones propias de la responsabilidad contractual: Galán Barrera, D. (2003) La compraventa internacional de mercaderías y su integración en el ordenamiento jurídico colombiano. Criterio Jurídico, Santiago de Cali-Colombia Nº pp. 113.

28 Roberts, H. (2011) Riley on Business Interruption Insurance, Thomson Reuters, Londres, p. 323.

29 El tamaño de la empresa debe necesariamente ser tenido en cuenta: Roberts, H. (2011) Riley on Business Interruption Insurance, Thomson Reuters, Londres, p. 322.

30 Landel, J. Red. (2016) Pertes d'exploitation, Titre 1, Chapitre 1, Dictionnaire permanente droit des assurances, EINet, No. 22.

31 JurisClasseur Responsabilite civile et Assurances, 2003. Fasc. 521 : Assurances Terrestres. Assurances relatives aux biens, Pertes d'exploitation. 
empresariales $^{32}$. Así, es una distinción dogmática que la garantía de lucro cesante no cubre en sí misma el establecimiento de comercio, que es un elemento permanente del patrimonio de la empresa, sino que se encarga de los dividendos, utilidades y gastos de funcionamiento durante un cierto periodo ${ }^{33}$.

Esta garantía tiene como finalidad cubrir situaciones de interrupción de la unidad de explotación económica sin que puedan hacer parte de ello los eventos que son inherentes al riesgo de empresa ${ }^{34}$. Así, dentro de la cobertura no se tienen en cuenta la disminución de la producción o de las ventas, las consecuencias de las fluctuaciones financieras, las huelgas o interrupciones de trabajo y demás situaciones que, controlables o incontrolables por el empresario, no pueden ser asegurables por este concepto ${ }^{35}$.

Un siniestro que afecta el ejercicio empresarial puede tener consecuencias relativas o devastadoras. Así, puede ir desde el caso del incendio que afecta el uso del local arrendado sin que los clientes sufran perturbación del flujo de productos, hasta aquel incidente en el que la fábrica fue completamente destruida sin que ninguna solución de reemplazo pueda encontrarse de forma suficientemente rápida para evitar la desaparición de la clientela ${ }^{36}$. Es por ello que la garantía de lucro cesante tiene por objeto permitir al empresario retomar la actividad económica y compensar las consecuencias de la interrupción de ésta, bajo la condición de que se trate de una interrupción limitada en el tiempo, excluyéndose así los casos de cierre definitivo. Se entiende entonces que la cesación definitiva de actividades que tiene lugar después del siniestro impide la aplicación de la garantía de lucro cesante ${ }^{37}$, aunque se afirma que ella alcanza a

32 Es por ello que la doctrina subraya la particular obligación de información del intermediario de seguros sobre le funcionamiento de este tipo de amparos: Cleary, N. (2015) Brokers' duties and business interruption insurance, Bloomsbury Professional, Professional Negligence, WestLaw.

33 Landel, J. Red. (2016) Pertes d'exploitation, Titre 1, Chapitre 1, Dictionnaire permanente droit des assurances, ElNet, No. 19.

34 Dentro de este riesgo se incluyen los comportamientos que originan la responsabilidad contractual de la empresa: Dugdale, T. (2207) Limitation periods and a "continuing" duty of care, Professional Negligence, Bloomsbury Professional, WestLaw.

35 Landel, J. Red. (2016) Pertes d'exploitation, Titre 1, Chapitre 1, Dictionnaire permanente droit des assurances, ElNet, No. 19.

36 Landel, J. Red. (2016) Pertes d'exploitation, Titre 1, Chapitre 1, Dictionnaire permanente droit des assurances, ElNet, No. 19.

37 Cass. 2e civ., 7 oct. 2010, n 09-70.264 (Francia) citada por Landel, J. Red. (2016) Pertes d'exploitation, Titre 1, Chapitre 1, Dictionnaire permanente droit des assurances, ElNet, Section 5, No. 19. 
operar hasta el momento en que el asegurado tenga conocimiento de la imposibilidad de continuar con la actividad comercial ${ }^{38}$.

III. Tratándose de una garantía generalmente complementaria, la declaración de riesgos sobre la productividad empresarial es especialmente importante ${ }^{39}$. Sin embargo, en algunas jurisdicciones, en los contratos cuya cobertura se extiende a diferentes riesgos, la reducción proporcional de la indemnidad no se aplica si la declaración inexacta no tuvo influencia directa en la tarificación de la prima relativa al riesgo de pérdida económica $^{40}$. Más aún algunos contratos otorgan la facultad al asegurador de renunciar a la sanción de la regla proporcional derivada de la divergencia entre los márgenes financieros declarados y la pérdida, de manera que el seguro pueda operar sin que se proceda a una evaluación de la pérdida real al momento del siniestro ${ }^{41}$.

IV. La garantía de lucro cesante en principio surge como un complemento de cobertura para las pérdidas consecutivas causadas con la destrucción o depreciación de los bienes de la empresa por efecto del incendio, la explosión, los atentados y las catástrofes naturales. Sin embargo, en la actualidad también es comercializada aparejada al amparo de riesgos de responsabilidad civil de la empresa, la confiscación y retiro de productos, el deceso de dirigentes, el transporte de mercancías o de los daños a equipos eléctricos o informáticos. Es así que esta garantía es especialmente relevante para las empresas que dependen en gran medida de uno o varios proveedores difícilmente reemplazables ${ }^{42}$.

38 Landel, J. Red. (2016) Pertes d'exploitation, Titre 1, Chapitre 1, Dictionnaire permanente droit des assurances, ElNet, No. 19.

39 El hecho de que estas garantias sean comunmente complementarias a otro contrato, exige que el asegurado sea especialmente cuidadoso en el cumplimiento de las obligaciones impuestas por el articulo 1076 del Codigo de Comercio, como recientemente lo ha recordado la Superintendencia Financiera de Colombia, Concepto 2015083405-002 del 16 de octubre de 2015.

40 Cass. 1re civ., 8 juill. 1997, $\mathrm{n}^{\circ}$ 95-17.069, n 1319 P, (Francia) y CA Paris, ch. 2-5, 27 oct. 2009, $n^{\circ}$ 07/20347 (Francia) citadas por Landel, J. Red. (2016) Pertes d'exploitation, Titre 1, Chapitre 1, Dictionnaire permanente droit des assurances, ElNet, No. 19.

41 Landel, J. Red. (2016) Pertes d'exploitation, Titre 1, Chapitre 1, Dictionnaire permanente droit des assurances, ElNet, No. 26.

42 Landel, J. Red. (2016) Pertes d'exploitation, Titre 1, Chapitre 1, Dictionnaire permanente droit des assurances, EINet, Section 3. 


\section{Operación de la cobertura de lucro cesante en forma inglesa}

La operación de la garantía puede apreciarse desde la perspectiva de los ingresos empresariales (i), de la estimación del monto de cobertura (ii), de la causa del siniestro (iii), del periodo de cobertura (iv), de las limitaciones a la cobertura (v) yendo hasta la atribución de la indemnidad (VI).

I. Durante un periodo normal de explotación los cargos fijos y los gastos generales permanentes son asumidos por los ingresos brutos. Sin embargo, ocurrido un siniestro estos montos no podrán ser arrogados a dichas entradas. Un siniestro va causar en todos los casos una disminución o incluso una interrupción de la actividad de la empresa, implicando de esta manera un menoscabo del volumen de negocios. Empero, las cargas fijas no serán necesariamente reducidas en la misma proporción que los ingresos netos ${ }^{43}$. Aunque, en cierta medida, presentado el accidente, las cargas variables pueden verse aminoradas, igualmente que la compra de materias primas, la empresa será obligada de resistir nuevos gastos frente a los cuales no existen o no son disponibles las reservas financieras necesarias. Es en este contexto que el seguro de lucro cesante surge para proteger la actividad empresarial.

II. El seguro cubre períodos de readaptación de una empresa hasta lograr el mismo nivel de producción que existía antes del siniestro. La Corte Suprema consideró que la suma a cargo del asegurador se establece a través de la estimación de las utilidades brutas siguiendo como guía los resultados comerciales o financieros del año anterior y teniendo en cuenta los eventuales aumentos o las condiciones del nuevo periodo ${ }^{44}$. Es de este modo que la Corte perennizó en Colombia la aplicación del principio indemnizatorio a la garantía de lucro cesante cuyo objeto es la protección del ingreso empresarial, principio que rige su operación incluso en los casos en que la indemnización es tarifada según lo acordado entre las partes o en los que un monto de pérdida máxima ha sido pactado. Valga la pena mencionar un precedente en el que se consideró que si la productividad mejoró en momentos posteriores al siniestro, y

43 JurisClasseur Responsabilite civile et Assurances, 2003. Fasc. 521: Assurances Terrestres. Assurances relatives aux biens, Pertes d'exploitation.

44 Página 20 párrafo 10 de la Sentencia. 
a pesar de éste, dicha recuperación no puede ser la base de cálculo para la garantía de lucro cesante ${ }^{45}$.

III. Esta garantía, que nace como un complemento por las pérdidas causadas en el siniestro de incendio y terremoto, exige una búsqueda estricta de la relación entre la pérdida financiera alegada y la causa de la misma ${ }^{46}$. Es por ello que la destrucción de un equipo o inmueble no es suficiente por sí misma para establecer la realidad de la pérdida reclamada ante el asegurador, sino que un nexo causal entre el siniestro y la pérdida debe ser objetivamente establecido como método para limitar un enriquecimiento sin causa ${ }^{47}$. En efecto, en estos casos es común que los aseguradores exijan, para que la garantía sea activada, una interrupción efectiva del negocio lo que excluye las hipótesis de una simple afectación del flujo comercial ${ }^{48}$. Sin embargo, no está legitimado el asegurador para afirmar que en un tal evento se trata de una mera pérdida de oportunidad económica puesto que mientras que ésta es un alea que depende de un evento futuro e incierto el lucro cesante existe desde que la perturbación de la propiedad haya sido demostrada, así como su incidencia en la actividad de explotación económica. Es por ello que, en esas circunstancias, en las que una perturbación de la actividad comercial está debidamente probada, el asegurador no podrá desconocer la existencia del daño, aunque naturalmente le será dable contestar el monto del perjuicio solicitado ${ }^{49}$. La cobertura puede ser activada cuando se trató de un siniestro afectando, por ejemplo, a un establecimiento de comercio vecino y que imposibilita el acceso a los locales de la empresa asegurada o cuando el depositario sufre un incendio que destruye la cosa guardada y pierde con ello la posibilidad de ganancia ${ }^{50}$, pero será el resultado adverso en caso de cierre, huelga, ocupación ilícita de un local

45 Sugar Hut Group Ltd v AJ Insurance Queen's Bench Division (Commercial Court) (Reino Unido) 20 October 2014 [2014] EWHC 3352 (Comm), Judge: Eder J.

46 JurisClasseur Responsabilite civile et Assurances, 2003. Fasc. 521 : Assurances Terrestres. Assurances relatives aux biens, Pertes d'exploitation.

47 CAA Lyon Section 2, 4 juin 1998, n 95LY00572 (Francia) citada por Landel, J. Red. (2016) Pertes d'exploitation, Titre 1, Chapitre 1, Dictionnaire permanente droit des assurances, ElNet.

48 Rossi M. A. (1998) Business interruption insurance coverage issues to consider for claims presentation and policy placement or renewal. International Insurance Law Review, Int. I.L.R. 71WestLaw.

49 Castela, C. (2013) Perte d'exploitation: réparation intégrale. L'actualité juridique propriété immobilière, 2013 p.757 Dalloz.

50 Ejemplo mencionado en: Gómez Sánchez, C. A.; Martínez del Río Samper, N. (2012) El interés asegurable como un elemento esencial del contrato de seguro de daños. Revista Ibero-Latinoamericana de Seguros, Bogotá (Colombia), 36(21): 13-36, enero-junio de 2012. 
o en caso de una sanción administrativa, pues en tales casos la garantía no está llamada a ser puesta en marcha ${ }^{51}$. Tratándose del transporte de mercancías, los retardos y el daño que impacta al medio de transporte pero que no afecta las mercancías aseguradas en sí mismas, pueden ser excluidos de cobertura ${ }^{52}$.

IV. El seguro de lucro cesante interviene durante un lapso de tiempo denominado periodo de indemnidad que corresponde al tiempo durante el cual los resultados de la empresa son afectados por el siniestro. Este periodo comienza el día del siniestro y termina al final de término establecido en las condiciones particulares del contrato. En las etapas precontractuales, la determinación de este lapso es fundamental puesto que un periodo de indemnidad muy corto, si bien reduce el precio de la prima del seguro, puede tener consecuencias fatales en caso de siniestro ${ }^{53}$ ya que la garantía va a cesar en una fecha alejada del momento en que pueden retomarse las actividades ${ }^{54}$. La definición de dicho periodo va a depender de la vulnerabilidad del negocio, de los riesgos propios de cada sector y de la posible incidencia que tendría un siniestro sobre la existencia y productividad de la empresa ${ }^{55}$. Por ello, los costos necesarios para el mantenimiento de la explotación durante un periodo de interrupción deberán ser tenidos en cuenta para definir el periodo de indemnidad pertinente. Al respecto es una regla aplicada por las cortes el hecho de que es el asegurado quien debe mesurar el monto de cobertura, pero también que el intermediario de seguros debe informar y aclarar al asegurado sobre el funcionamiento de la garantía de lucro cesante, así como los elementos necesarios a un cálculo adecuado ${ }^{56}$.

En los casos de eventos mayores, concernientes a la destrucción total por incendio o demolición, una cobertura de al menos 12 meses se impo-

51 Landel, J. Red. (2016) Pertes d'exploitation, Titre 1, Chapitre 1, Dictionnaire permanente droit des assurances, ElNet, No. 12.

52 Ibidem.

53 Como el infraseguro: Roberts, H. (2011) Riley on Business Interruption Insurance, Thomson Reuters, Londres, p. 170.

54 Landel, J. Red. (2016) Pertes d'exploitation, Titre 1, Chapitre 1, Dictionnaire permanente droit des assurances, ElNet, Choix de la période d'indemnisation, No. 41.

55 Kullman, J.; Habib-Deloncle L. et al. (2016) Lamy Assurances, Lamyline, Assurances dommages, Assurances des biens de l'entreprise, No. 1737.

56 Eurokey Recycling Ltd v Giles Insurance Brokers Ltd Queen's Bench Division (Commercial Court) [2014] EWHC 2989 (Comm) (Inglaterra) [2015] 2 All E.R. (Comm) 55 (QBD (Comm), Judge: Blair J. 
ne ${ }^{57}$ como solución propicia al mantenimiento de la empresa, lo cual es a su vez un argumento persuasivo para la comercialización del producto.

En otros casos, la empresa afectada por un siniestro se ve en dificultad para retomar sus actividades. Una primera hipótesis se tiene en la imposibilidad de reiniciar operaciones en el mismo sitio del accidente, lo que hace necesario una reinstalación en otros locales. En este caso la indemnidad será limitada a un monto que represente los ingresos que la empresa hubiera reflejado si la actividad hubiera iniciado en el mismo $\operatorname{sitio}^{58}$. Una segunda hipótesis ocurre cuando los locales asegurados pueden dividirse en unidades operacionales separadas. En efecto, si una de ellas es afectada impidiendo el desarrollo global del ejercicio industrial, el amparo debe ser activado; pero esta circunstancia no tendrá lugar si el siniestro afecta una única unidad ${ }^{59}$. Una tercera hipótesis se haya en la interrupción originada en un evento independiente de la voluntad del asegurado, específicamente el caso fortuito, en el cual, como ha sido manifestado, la garantía puede cubrir las consecuencias del siniestro hasta el momento en que el asegurado haya tenido conocimiento de la imposibilidad de continuar con su actividad ${ }^{60}$. Es de esta manera que la no continuación de la actividad empresarial impacta el contrato de seguro, incluso en casos en que el empresario puede llevar a cabo otros procesos de la cadena productiva, en otras dependencias de la compañía que no hacían parte de los bienes asegurados bajo el mismo seguro que aquel que cubría el local siniestrado ${ }^{61}$.

V. Como ha sido mencionado, en este tipo de contratos algunos productos permiten al asegurador renunciar a la aplicación del principio de proporcionalidad lo que permite proveer una garantía inmediata desde la presentación del siniestro ${ }^{62}$. Para el correcto funcionamiento de un tal

57 JurisClasseur Responsabilite civile et Assurances, 2003. Fasc. 521 : Assurances Terrestres. Assurances relatives aux biens, Pertes d'exploitation.

58 JurisClasseur Responsabilite civile et Assurances, 2003. Fasc. 521 : Assurances Terrestres. Assurances relatives aux biens, Pertes d'exploitation.

59 Rossi M. A. (1998) Business interruption insurance coverage issues to consider for claims presentation and policy placement or renewal. International Insurance Law Review, Int. I.L.R. 71WestLaw.

60 Aunque se interpretó que en el caso fortuito, necesario para activar la cobertura, no se podía incluir la enfermedad del administrador de la sociedad, en: Cass. 1re civ., 29 mars 1989: Juris-Data n ${ }^{1989-}$ 001696 (Francia); Resp. civ. et assur. 1989, comm. $\mathrm{n}^{\circ} 246$.

61 Cass. 1re civ., 28 oct. 1991 (Francia) : Resp. civ. et assur. 1992, comm. 206.

62 Kullman, J.; Habib-Deloncle L. et al. (2016) Lamy Assurances, Lamyline, Assurances dommages, Assurances des biens de l'entreprise, No. 1741. 
acuerdo, el asegurado deberá haber declarado fielmente los elementos constitutivos del margen bruto de negocios o que en cualquier caso se determine con anticipación el mayor detrimento patrimonial que puede llegar a sufrir el asegurado ${ }^{63}$. Sin embargo, en este caso, cuando un siniestro grave o total tiene lugar, la garantía podría ser insuficiente porque la indemnidad será limitada a los montos declarados ${ }^{64}$. Ahora, cuando el asegurador ha renunciado a valerse de la regla proporcional y el siniestro no fue total, no podrá afirmarse que la totalidad del margen bruto fue perdido y es por ello que una limitación contractual de la indemnidad opera en este sentido ${ }^{65}$.

Es frente a este tipo de estipulaciones contractuales que se ha denominado a los seguros de daños como de mera indemnización y no de indemnización plena pues el monto a indemnizar por parte del asegurador no necesariamente corresponde al valor asegurado, sino que puede ser aquel que resulte del daño o perjuicio efectivamente ocasionado al patrimonio del tomador, sin que el valor a indemnizar llegue a ser mayor a la suma asegurada ${ }^{66}$.

Cuando una indemnización tarifada fue pactada entre las partes, este forfait puede estipularse en un monto inferior al valor de las sumas aseguradas, lo que se denomina "de pérdida máxima" ${ }^{67}$. Pero en cualquier caso, el asegurador no está obligado a indemnizar más que el monto real de las pérdidas y es por ello que la extensión de los efectos del siniestro deberá ser siempre objeto de verificación ${ }^{68}$. Además de lo anterior es común

63 Gómez Sánchez, C. A.; Martínez del Río Samper, N. (2012) El interés asegurable como un elemento esencial del contrato de seguro de daños. Revista Ibero-Latinoamericana de Seguros, Bogotá (Colombia), 36(21): 13-36, enero-junio de 2012.

64 Preocupación expresada por un sector de la doctrina, como se expresa en: Botero Morales, B. (2009), El Seguro de Lucro Cesante Forma Inglesa, Pérdida de Utilidad Bruta, Tesis de Grado, Pontificia Universidad Javeriana, Facultad De Economía.

65 Landel, J. Red. (2016) Pertes d'exploitation, Titre 1, Chapitre 1, Dictionnaire permanente droit des assurances, ElNet, Garantie inférieur à la marge, No. 28.

66 Como se menciona en un obiter de la Sentencia No. 28278 de la Sección Tercera del Consejo de Estado de febrero 12 de 2015, C. P. Carlos Alberto Zambrano, pagina 19 parrafo 2o.

67 La doctrina menciona que bajo una cláusula de este tipo la cobertura de las pequeñas empresas es insuficiente aun cuando en la practica la garantía pueda ir hasta un año, en: JurisClasseur Responsabilité civile et Assurances, 2003. Fasc. 521 : Assurances Terrestres. Assurances relatives aux biens, Pertes d'exploitation.

68 En este tipo de contratos con un monto diario fijo se excluye la multiplicación de dicho monto por el número total de días de interrupción: Cass. 1re civ., 17 nov. 1987 : Resp. civ. et assur. 1988, comm. 370 (Francia) citada por: JurisClasseur Responsabilité civile et Assurances, 2003. Fasc. 521: Assurances Terrestres. Assurances relatives aux biens, Pertes d'exploitation. 
que los contratos prevean una cláusula de ajustabilidad. Esta cláusula es usada ante la dificultad para una empresa de apreciar previamente la evolución financiera sobre varios años ${ }^{69}$. Además de lo anterior, en estos contratos el deducible es frecuentemente pactado por cada siniestro y puede ser integrado a la poliza como un lapso temporal, como un valor económico, como un porcentaje del margen bruto o como un porcentaje de la indemnidad, además de poder calcularse por actividad empresarial o por departamento ${ }^{70}$.

VI. El asegurador pagará la indemnidad al asegurado, al propietario, al arrendatario de los locales o al beneficiario que fue designado en el contrato. Sin embargo, se ha considerado que no es procedente que un acreedor busque satisfacer su crédito en contra de la empresa a través del contrato de seguro de lucro cesante puesto que dicha garantía no hace parte de los elementos integrantes del patrimonio empresarial ${ }^{71}$. Es por ello que se consideró que el contrato de seguro de lucro cesante no es impactado por la hipoteca que grava el establecimiento de comercio incendiado y por ello el banco no puede pretender a que éste le sea atribuido ${ }^{72}$. En dicha ocasión se consideró que a pesar de que una disposición legislativa ordenaba beneficiar al acreedor de los contratos de seguros cubriendo el bien sujeto a la hipoteca, dicha norma era inaplicable a los contratos de seguro de lucro cesante puesto que éstos no amparan el bien gravado, sino las consecuencias que su destrucción representan para el asegurado ${ }^{73}$. Es así que en este sentido revenimos sobre la clasificación dada en §1.B.I. según la cual la garantía de lucro cesante es distinta y tiene reglas propias e independientes de aquellas que rigen el contrato de daños que cubre el bien inmueble y no sus frutos.

69 JurisClasseur Responsabilité civile et Assurances, 2003. Fasc. 521 : Assurances Terrestres. Assurances relatives aux biens, Pertes d'exploitation.

70 JurisClasseur Responsabilité civile et Assurances, 2003. Fasc. 521 : Assurances Terrestres. Assurances relatives aux biens, Pertes d'exploitation.

71 Cass. 1re civ., 9 nov. 1999: Juris-Data n 1999-003917 (Francia); Resp. civ. et assur. 2000, comm. 68.

72 Derruppé, J. (2000) L'indemnité d'assurance pour perte d'exploitation n'est pas un élément du fonds de commerce. Revue trimestrelle de droit commercial et economique, Dalloz. RTD Com. 2000 p.72.

73 Piedelièvre, S. (2000) La perte d'exploitation n'entre pas dans l'assiette du nantissement d'un fonds de commerce. Recueil Dalloz 2000 p.390. 


\section{LA PRESCRIPCIÓN DE LA GARANTÍA DE LUCRO CESANTE}

Como fue descrito en las secciones §I.A.1 y §I.A.2, el debate presentado en el recurso extraordinario resuelto en la Sentencia de casación de 15 de junio de 2016 se subsume a la determinación del elemento que activa el término de la prescripción ordinaria, tratándose del amparo de lucro cesante en la forma inglesa, sea este la fecha del incendio o sea la fecha en que se restableció el normal funcionamiento de la empresa ${ }^{74}$. Se responderá entonces en primera medida la pregunta sobre la prescripción propia del derecho de daños y de la garantía de lucro cesante en forma inglesa (A) para luego perfilar la autoridad que representa la Decisión de la Corte Suprema a través del exposición de la doctrina de los precedentes jurisprudenciales y las implicaciones del uso de una decisión de Common law en la confirmación de la dogmática aplicable en adelante en nuestro país (B).

\section{A. La prescripción en el derecho de daños}

En la Sentencia de 15 de junio de 2016, la Sala Civil recuerda el doble efecto del siniestro que, como realización del riesgo asegurado según el artículo 1072 del Código de Comercio, origina de un lado la obligación del asegurador (artículo 1054) y de otro constituye el hecho base de la acción (artículo 1081) ${ }^{75}$.

El seguro de daños es dirigido a la protección del patrimonio que podría ser afectado por la ocurrencia del siniestro y es por ello que se considera que, desde el punto de vista jurídico, los componentes base de la acción son distintos, esto es el hecho condicional y el evento dañino, lo cual responde también a una doble clasificación ${ }^{76}$ : de un lado, el hecho

\footnotetext{
74 Numeral 3.3 de la Sentencia de la Corte Suprema de 15 de junio de 2016.

75 Numeral 3.3.1 de la Sentencia de la Corte Suprema de 15 de junio de 2016.

76 La Corte Suprema ha decidido dicha doble clasificación desde una cuadragenaria jurisprudencia: ““El término de una y otra prescripción comienza a correr desde momentos distintos así: a) El de la ordinaria, a partir de cuándo el interesado (y ya se vio quiénes lo son) tuvo conocimiento o razonablemente pudo tenerlo, "del hecho que da base a la acción". Este hecho no es, no puede ser otro, que el siniestro, entendido éste, según el artículo 1072 ibídem, Como "la realización del riesgo asegurado", o sea del hecho futuro e incierto de cuya ocurrencia depende el nacimiento de la obligación de indemnizar a cargo del asegurador y correlativamente del derecho del asegurado o beneficiario a cobrar la indemnización" Sentencia del 07 de junio de 1977. Corte Suprema de Justicia, Sala de Casación Civil. Gaceta Judicial 2396. M.P. José María Esguerra Samper. Bogotá: 1977.
} 
condicional se refiere a la materialización de una circunstancia futura e incierta, mientras que de otro lado, el evento dañino no tiene lugar sino una vez es configurado el contenido o resultado obligacional ${ }^{77}$. Es por ello que se trata de una afectación patrimonial indirecta o mediata, porque ocurrido el accidente el perjuicio solo es verificable posteriormente y es así que se dice que en este tipo de contratos, el siniestro se acerca a la naturaleza de una condición preparatoria, más que a la de una causa determinante $^{78}$.

Recuerda la Corte que en este tipo de contratos es una circunstancia ineludible la verificación del perjuicio económico del asegurado, pues se trata de un amparo de estirpe patrimonial, lo que se conmueve con las consideraciones de la doctrina como fue manifestado anteriormente en la sección §I.B.2.V.

La iniciación del período prescriptivo sólo tiene lugar cuando fue superado el periodo evolutivo del riesgo, luego del hecho condicional y hasta la configuración definitiva del siniestro de lucro cesante que da origen pleno a la prestación asegurada ${ }^{79}$. Es de este modo que para la determinación del periodo durante el cual corre la prescripción en el seguro de daños se necesita establecer cuál es el elemento desencadenante de la garantía de lucro cesante (1) así como el momento en el cual tiene lugar la consolidación y exigibilidad de la obligación del asegurador (2).

\section{El elemento desencadenante de la garantia de lucro cesante}

Desde el punto de vista técnico, el hecho condicional y el evento dañino surgen simultáneamente. Sin embargo las consecuencias jurídicas no se originan sino cuando ambos son concurrentes, independientemente del momento específico de la configuración de uno y otro ${ }^{80}$. Para ilustrar esta exigencia jurídica menciona la Corte que un incendio que no produce efectos dañinos no implica una obligación indemnizatoria o también el

77 Página 17 párrafo 2o de la Sentencia de la Corte Suprema de 15 de junio de 2016.

78 Gómez Sánchez, C. A.; Martínez del Río Samper, N. (2012) El interés asegurable como un elemento esencial del contrato de seguro de daños. Revista Ibero-Latinoamericana de Seguros, Bogotá (Colombia), 36(21): 13-36, enero-junio de 2012.

79 Página 18 párrafos 1 y y 2o de la Sentencia de la Corte Suprema de 15 de junio de 2016.

80 Numeral 3.3.1 de la Sentencia de la Corte Suprema de 15 de junio de 2016. 
caso en que se verifica el perjuicio, pero éste se atribuye a una causa totalmente ajena.

La finalidad del seguro de lucro cesante en forma inglesa, conceptuó la Corte Suprema, es la protección de la actividad económica del asegurado durante el período de paralización de la propiedad, de la empresa o del elemento generador de la renta o utilidad ${ }^{81}$. Entonces, el riesgo asegurado no es propiamente el hecho condicional (incendio) sino el evento dañino, esto es, el periodo en que ocurre una disminución de los ingresos, correspondiente al ciclo de readaptación de la empresa que tiene lugar después del siniestro, hasta el logro de un nivel de productividad similar a aquel anterior a la destrucción ${ }^{82}$.

El riesgo tiene una forma evolutiva desde que acaece el hecho condicional pero no cobra actualidad -dejando de ser meramente potencialsino hasta que se generó un perjuicio económico en el patrimonio del asegurado. Empero, en el interregno no se ha configurado el siniestro de lucro cesante sino que se encuentra en un periodo de consolidación, siendo por ello a ese estadio una mera expectativa de derecho sin tener, hasta dicho momento, consecuencias jurídicas ${ }^{83}$. Es así que se hace necesario esperar el tiempo indispensable para establecer la magnitud del daño ${ }^{84}$.

\section{Consolidación y exigibilidad de la obligación del asegurador}

El seguro busca dar seguridad y estabilidad social frente a los riesgos que rodean la vida empresarial. El contrato de seguro implica una obligación a cargo del asegurador cuya forma es la condición que en según el artículo 1054 del Código de Comercio es el riesgo que no depende de la voluntad de las partes y que origina la obligación del asegurador. El riesgo exige entonces que sobrevenga un hecho por obra del azar, del alea y además que afecte patrimonialmente a un sujeto de derecho ${ }^{85}$.

81 Página 15 párrafo 3o de la Sentencia de la Corte Suprema de 15 de junio de 2016.

82 Página 16 párrafo 2o de la Sentencia de la Corte Suprema de 15 de junio de 2016.

83 En efecto, del comportamiento del asegurado frente al siniestro pueden desprenderse consecuencias de cobertura. Además, es un momento en el cual se inicia un periodo de ardua investigación, avaluó y determinación del siniestro y sus consecuencias inmediatas y futuras.

84 Página 19 párrafo 1o de la Sentencia de la Corte Suprema de 15 de junio de 2016.

85 Página 14 párrafo 1o de la Sentencia de la Corte Suprema de 15 de junio de 2016. 
El contenido económico del riesgo abre entonces la posibilidad de demandar la indemnización ante la pérdida y detrimento patrimonial (artículo 1054 del Código de Comercio). De lo contrario, se trata de una condición suspensiva en estado latente, virtual o potencial (artículo 1530 y 1536 del Código Civil) ${ }^{86}$.

Pero para que la obligación de pagar la indemnidad en la garantía de lucro cesante sea exigible otra condición es requerida. En efecto, tratándose de este tipo de contrato la obligación del asegurador no es pura y simple puesto que la indemnización es postergada ${ }^{87}$. Para que nazca a la vida jurídica se exige su consolidación que solo tiene ocurrencia cuando se verifica la ocurrencia del riesgo asegurado, esto es la disminución de ingresos (como se mencionó en la sección §II.A.1) puesto que, si bien el derecho nace con el acaecimiento del siniestro, la obligación no se halla en estado de exigibilidad ${ }^{88}$ sino hasta que el evento dañino tiene lugar ${ }^{89}$.

Es por ello que en la garantía de lucro cesante en forma inglesa, la condición se torna en causa eficiente y remota, mientras que la génesis del contenido obligacional no tiene lugar sino hasta la verificación de las pérdidas operacionales generadas con la obstaculización de la actividad económica $^{90}$.

Para la Corte, si bien la obligación nació con la materialización del riesgo, su exigibilidad queda íntegramente diferida hasta la readaptación al estado inicial de la empresa ${ }^{91}$. Es en este sentido que se menciona que, siguiendo el artículo 1542 del Código Civil, la obligación deviene exigible cuando la condición ha sido verificada totalmente, porque antes de la pérdida económica la exigibilidad se encuentra en estado potencial, de latencia y en forma abstracta ${ }^{92}$.

\footnotetext{
86 Página 14 párrafo 2o de la Sentencia de la Corte Suprema de 15 de junio de 2016.

87 Página 15 párrafo 1o de la Sentencia de la Corte Suprema de 15 de junio de 2016.

88 Página 17 párrafo 2o de la Sentencia de la Corte Suprema de 15 de junio de 2016.

89 Página 15 párrafo 2o de la Sentencia de la Corte Suprema de 15 de junio de 2016.

90 Página 16 párrafo 20 y página 32 párrafo 20 de la Sentencia de la Corte Suprema de 15 de junio de 2016.

91 Página 16 párrafo 2o de la Sentencia de la Corte Suprema de 15 de junio de 2016.

92 Página 17 párrafo 1o de la Sentencia de la Corte Suprema de 15 de junio de 2016.
} 
En conclusión, en la garantía de lucro cesante en forma inglesa el siniestro no es de estructuración inmediata sino que jurídicamente se entiende realizado y consolidado su contenido obligacional en dos posibles momentos: al vencimiento del término de indemnidad señalado en la póliza, o antes de éste, si la empresa logró su recuperación económi$\mathrm{ca}^{93}$. Un argumento de orden práctico de la parte actora fue reconocido por la Corte: el lapso de tiempo que transcurre durante el periodo de indemnidad es necesario para verificar las ganancias frustradas y los gastos de funcionamiento ${ }^{94}$. Es apenas lógico que tratándose de un seguro de bienes, la determinación del monto a indemnizar sólo pueda ser calculado una vez se verifique el daño y su magnitud. Al respecto sea de mencionar que se consideró ${ }^{95}$ que la reclamación a la aseguradora, para efectos del comienzo del término de pago que pesa sobre ésta según el artículo 1080 del Código de Comercio, no podía tener lugar sino una vez demostrada la ocurrencia del siniestro y la cuantía de cada uno de los rubros correspondientes a los diversos amparos en los contratos en los cuales una única póliza tiene pluralidad de coberturas.

De la suma de todos estos elementos formula la Corte la ratio decidendi según la cual la llegada al culmen del periodo de indemnidad es el presupuesto para habilitar la reclamación contra la aseguradora ya que solo hasta dicho momento se pueden establecer los montos objeto de indemnización ${ }^{96}$.

Así, si se trató de un contrato en el que ciertos bienes fueron objeto de garantía, así mismo que la pérdida de beneficios esperados, la base de la acción es diferente en cada caso, puesto que en el primero es la ocurrencia del hecho condicionante y en la segundo es la consolidación del contenido obligacional del seguro. Sin embargo, aunque integrados en un mismo contrato, los hechos que configuran el siniestro en uno y otro no afectan el momento en que comienza a correr la prescripción para cada uno puesto que, afirma la Corte, la aplicación de la prescripción extintiva depende de la posición que la persona tenga en relación con

93 Página 25 párrafos 3 o y 4o, numerales 3.4.1 y 3.4.2. de la Sentencia de la Corte Suprema de 15 de junio de 2016.

94 Página 26 párrafo 1o de la Sentencia de la Corte Suprema de 15 de junio de 2016.

95 Laudo Arbitral C.I. Avetex S.A. contra BBVA Seguros Colombia S.A. (Colombia) 5 de diciembre de 2008, Pdte. Pedro José Bautista Moller.

96 Página 26 párrafo 3o de la Sentencia de la Corte Suprema de 15 de junio de 2016. 
el hecho que motiva la acción ${ }^{97}$. Es el mismo asegurado pero para cada garantía tiene una posición diferente pues el ámbito patrimonial en uno y otro es divergente.

Ciertamente, sobre el punto de la diferenciación de la base de las acciones, esta decisión de la Corte Suprema de Justicia de Colombia sigue los avances de la tradición napoleónica. En efecto, la Sentencia Nro. 92-13286 de 21 de marzo de $1995^{98}$ de la Sala Civil de la Corte de Casación de Francia determinó que, aun si dos garantías fueron acordadas bajo un mismo contrato, específicamente los daños materiales a un inmueble y el lucro cesante, ambos amparos no constituyen obligaciones indivisibles ${ }^{99}$ puesto que el objeto de cobertura es diferente en cada caso $^{100}$ y por ello las reglas de cómputo del termino de prescripción van a variar entre uno y otro $^{101}$.

\section{B. La configuración del precedente judicial}

La Asamblea Nacional en la Constitución de 1991 y la Corte Constitucional en las Sentencias C-104 de 1993 y C-836 de 2001 lideraron la adopción en Colombia de un sistema de precedentes jurisprudenciales como fuente del derecho ${ }^{102}$. Este cambio implicó un desplazamiento de la tradición jurídica latina donde la jurisprudencia de las cortes era un mero criterio auxiliar, hacia la introducción de la doctrina de precedentes, la cual es un elemento propio del sistema de Common Law. Esta modificación implicó que los jueces estarían en adelante en el centro de

97 Página 27 párrafos 20 y 3o de la Sentencia de la Corte Suprema de 15 de junio de 2016.

98 Cour de cassation (1re Ch. civ.), 21 mars 1995, n. 92-13286, S.A.R.L. Le Pénélope et autres c/ Compagnie L'Allianz (Francia).

99 Aunque este criterio de la indivisibilidad de obligaciones, proveniente del Código Civil, puede ser inexacta, según la doctrina, ya que tratándose de un contrato de seguros, hay un único deudor pero garantías diferentes: Mayaux, L. (1995) Interruption de la prescription. Limitation à la police visée dans la demande. Revue générale du droit des assurances - 01/04/1995 - n¹995-2 - page 345, RGDA1995345.

100 Posteriormente la Sentencia No. 09-11940 de 13 de marzo de 2009 la Corte de Casación confirmó esta posición sobre la independencia de garantías que surgen de un mismo siniestro: Cour de cassation (2e Ch. civ.), 13 mars 2009, n o 09-11940, SCI Gravel c/ Société AGF (Francia).

101 Abravanel-Jolly, S. (2010) Deux contrats souscrits par le Syndicat et par la SCI. Garantie réclamée sur le seul fondement du contrat souscrit par le Syndicat. Revue générale du droit des assurances 01/01/2010 - n² 2010-01 - page 88, RGDA201088.

102 Contreras Calderón, J. A. (2011) El precedente judicial en Colombia: Un análisis desde la teoría del derecho. Revista Facultad de Derecho y Ciencias Políticas. Vol. 41, No. 115 / p. 331-361. 
la protección de derechos ${ }^{103}$. Es en ejercicio de dicha herramienta que la Corte Suprema de Justicia utilizó una decisión extranjera para analizar el caso ${ }^{104}$ y tomar la Decisión de 15 de junio de 2016. No cabe duda que tal elección por parte de la Corte Suprema de Colombia, de analizar la jurisprudencia extranjera para decidir un caso de derecho interno, respondió a un interés no solo de actualizar el estado del derecho en un área típicamente compleja y técnica, sino de fundamentar su decisión partiendo de criterios establecidos en sistemas extranjeros donde ya se ha pasado por estas discusiones hace muchos años, situación que sin duda es legítima si se tiene en cuenta que la Corte Constitucional, el Consejo de Estado y la Corte Suprema de Justicia no han dudado en recurrir al análisis expresado en decisiones extranjeras para juzgar casos que afectan el ámbito nacional, especialmente cuando falla desde vacíos jurisprudenciales sobre un punto de derecho irresoluto hasta ese momento en el derecho nacional.

Pasaremos entonces a delimitar el precedente jurisprudencial extranjero utilizado por la Corte Suprema Colombiana en su decisión de 15 de junio de 2016 (1) para luego mencionar cual es la aplicación que en Common Law se le ha dado a la pregunta de la activación del seguro de lucro cesante (2).

\section{El precedente sentado por la Corte y los elementos de autoridad utilizados}

Como fue explicado, la Sala Civil de la Corte Suprema de Justicia determinó que el evento desencadenante de la garantía de lucro cesante es la pérdida financiera subsiguiente al hecho generador $(\S$ II.A.1.) y por ello el término de la prescripción no comienza a correr sino una vez configurado el contenido obligacional del contrato de seguro (§ II.A.).

103 Dijo la Corte Constitucional: "El texto de la ley no es, por sí mismo, susceptible de aplicarse mecánicamente a todos los casos, y ello justifica la necesidad de que el juez lo interprete y aplique, integrándolo y dándole coherencia, de tal forma que se pueda realizar la igualdad en su sentido constitucional más completo" Sentencia C- 836 de 2001, Numeral 3.2.4.

104 No es la primera vez que se encuentran decisiones nacionales citando decisiones extranjeras, un ejemplo es la Sentencia de la Sala Civil de la Corte Suprema de Justicia de 21 de febrero de 2012, Rad. 00537-01, MP. William Namén Vargas. 
Para llegar a esta conclusión el Magistrado Ponente realizó un análisis de un precedente del Common Law, precisamente el caso Peloso v. Hartford Fire Insurance Co (1970) ${ }^{105}$, así como también se basó en el estudio de otras garantías análogas, como lo es la garantía de lucro cesante de forma americana.

En primera medida, en Peloso v. Hartford, la New Jersey High Court determinó que el término de prescripción de la acción derivada del seguro de incendio debió ser suspendido puesto que la aseguradora no objetó en un primer momento la garantía, sino que afirmó que iba a proceder a realizar investigaciones. Ante la ausencia de cobertura del siniestro, el asegurado demandó a la aseguradora encontrando que el plazo de prescripción estaba superado. Sin embargo, la New Jersey High Court declaró que el comportamiento del asegurador fue de mala fe al haber dejado pasar el tiempo so pretexto de realizar investigaciones. Por ello decidió que el plazo de prescripción tuvo necesariamente que estar interrumpido desde la fecha de la solicitud por el asegurado.

Si bien la Corte realizó una distinción (distinguished) ${ }^{106}$ del precedente de Peloso v. Hartford, dicha decisión hace parte de la esfera argumentativa que en adelante es disponible en Colombia para los jueces en las decisiones sobre derecho de seguros. En palabras de la Corte:

"Ese pronunciamiento judicial reviste singular importancia para el tema materia de estudio: como se dijo, constituye el punto inicial a partir del cual (...) es posible suspender el término de prescripción de las acciones derivadas del contrato de seguro"107.

Entonces, aunque Peloso v. Hartford no haya sido utilizado por la Corte para juzgar en concreto los hechos en la Sentencia de 15 de junio de 2016, se le reconoció expresamente valor conceptual y argumentativo en derecho interno ${ }^{108}$, más aún cuando en este caso la Corte Suprema

105 Peloso v. Hartford Fire Insurance Co 56 N.J. 514 (1970) 267 A.2d 498, Supreme Court of New Jersey (Estados Unidos), Judge: Schettino J.

106 Como lo menciona la Corte (pie de página 10 pagina 20 de la Sentencia) en este caso se trató de la orden de suspensión de un término de prescripción contractual y no legal, situación que confirma posteriormente en la página 33 párrafo 1o de la Sentencia de la Corte Suprema de 15 de junio de 2016.

107 Página 22 párrafo 3o de la Sentencia de la Sentencia de la Corte Suprema de 15 de junio de 2016.

108 En las jurisdicciones de Common Law, la citación de un precedente de otro país hace de dicha decisión derecho aplicable a nivel local: Chao-hung Chen, C. (2014) Measuring the Transplantation of English 
colombiana encontró que el asegurador había retrasado en más de un año la definición sobre la procedibilidad o no de la cobertura al haber solicitado a través del ajustador una serie de documentos y luego haber guardado silencio sobre si iba o no a amparar el siniestro reclamado ${ }^{109}$.

Sin duda alguna, la prudencia de los jueces les exige hacer cambios lentos pero a pasos seguros. Por ello haber argumentado desde Peloso $v$. Hartford abre un espacio discursivo para casos en que, como el presente, fue la aseguradora misma quién retardó la decisión de si cubrir o no el siniestro, dejando con ello correr el plazo de la prescripción. Ciertamente una inflexión a la rigidez propia de las reglas de prescripción puede verse a mediano plazo, una vez que la Corte Suprema de Justicia ha encontrado casos en los cuales el acto del asegurador pudo haber contribuido con el transcurso del término.

En segunda medida en la Sentencia de 15 de junio de 2016 la Corte Suprema se menciona la garantía de lucro cesante en forma americana o de ganancias brutas. Encontró la Corte que este tipo de seguro es ilustrativo para la resolución del caso bajo análisis puesto que su exigibilidad no coincide con la realización del hecho condicionante y por ello el asegurado está legitimado para reclamar en un momento posterior al hecho generador de la pérdida ${ }^{110}$.

\section{La configuración del siniestro en la garantia de lucro cesante en Common Law}

No podemos sino admirar la calidad de la decisión de la Corte Suprema ${ }^{111}$ que echó mano de las mejores herramientas internacionales para determinar las nociones objeto de discusión judicial. Este método es de gran utilidad, más aún cuando los autores ratifican que los problemas que se presentan en la actualidad en la utilización de las pólizas de lucro cesante,

Commercial Law in a Small Jurisdiction: An Empirical Study of Singapore's Insurance Judgments between 1965 and 2012, Texas International Law Journal. 49, (3), 469-505. Research Collection School Of Law.

109 Página 2 párrafos 1 a 3, numerales 1.2 y 1.3 de la Sentencia de la Corte Suprema de 15 de junio de 2016.

110 Página 22 párrafo 4o de la Sentencia de la Corte Suprema de 15 de junio de 2016.

111 A pesar de no utilizar criterios vitales para la utilización de jurisprudencia de Common Law, como seguir el estilo de citación propio de este sistema o la determinación de la validez de la sentencia frente a decisiones de Altas Cortes que podrían tener más autoridad argumentativa. 
se repiten en las jurisdicciones de derecho de continental europeo, así como en las de Common law de Estados Unidos y Reino Unido ${ }^{112}$. Sin duda recorreremos un camino más corto si miramos hacia afuera donde los seguros en general tienen una mayor penetración social, lo que provoca un mayor desarrollo de su regulación. Sin embargo, trataremos de ubicar la pregunta sobre el momento de inicio de la garantía de lucro cesante en forma inglesa en el derecho de Common law a través de una decisión con mayor capacidad disuasiva ${ }^{113}$.

La decisión relevante frente al punto de derecho analizado es Loyaltrend Ltd v Creechurch Dedicated Ltd [2010] ${ }^{114}$. En este caso una comercializadora de ropa funcionaba en un local ubicado en el primer piso de un edificio. Una infiltración de agua tuvo lugar en el año 2003 y continuó hasta el 2006, aunque en el entretiempo el propietario realizó algunos trabajos de reparación. La comercializadora asegurada declaró el siniestro en agosto de 2005, afirmando que el problema no fue evidente sino hasta mediados de dicho año. Sin embargo, el asegurado reconoció que un defecto de nivelación fue encontrado en el piso del local por sus empleados en 2004. El asegurador objetó la reclamación bajo el argumento de que el asegurado desconoció su obligación de dar noticia oportuna del siniestro. La prueba del momento de la ocurrencia del siniestro correspondía al asegurado, más aún si como en este caso el momento exacto de ocurrencia del incidente era confuso, tratándose de un daño progresivo. El asegurado por su parte afirmaba que la póliza cubría las consecuencias de la interrupción de la actividad comercial como un opuesto al daño material que afectó al local donde se desarrollaba la actividad comercial. Sin embargo, para la Mercantile Court, en el contexto del amparo de interrupción de negocios, el siniestro tiene lugar en el momento de la afectación de la actividad comercial, más no aquel de la infiltración que causó el daño material del local ${ }^{115}$.

112 Rossi M.A. (1998) Business interruption insurance coverage issues to consider for claims presentation and policy placement or renewal. International Insurance Law Review, Int. I.L.R. 71 WestLaw.

113 La jerarquía en la cual se encuentra la Corte que emite la decisión, así como el país del cual proviene son elementos que se tienen en cuenta en los sistemas de Common Law para determinar su capacidad disuasiva.

114 Loyaltrend Ltd v Creechurch Dedicated Ltd Queen's Bench Division (Mercantile Court) (Reino Unido) 05 March 2010 [2010] EWHC 425 (Comm); [2010] Lloyd's Rep. I.R. 466, Judge: Mackie QC.

115 Parágrafo Nro. 33, Loyaltrend Ltd v Creechurch Dedicated Ltd. [2010]. 
Se demostró entonces que la infiltración inició en 2003 y fue evidente desde 2004, instante en el cual una disminución en los ingresos del asegurado comenzó a exteriorizarse. Sin embargo, la reclamación no se formuló al asegurador sino hasta agosto de 2005. Vale la pena mencionar la respuesta del juez a la vacilación del asegurado respecto del momento en el cual tuvo conocimiento del siniestro. Manifestó que al respecto existe un test instituido en Laker Vent Engineering Limited v Templeton Insurance Limited [2009] ${ }^{116}$ según el cual el asegurado debe declarar todo hecho que origine o que pueda llegar a originar una reclamación frente al asegurador ${ }^{117}$. Este test es objetivo y no subjetivo y es por ello que el asegurado debió declarar el incidente desde 2003.

La Mercantile Court sienta entonces precedente. La declaración del siniestro afectando el bien inmueble tenía que haber ocurrido en el momento en que el asegurado tuvo conocimiento de los hechos, incluso aun si, para efectos de la cobertura de la interrupción de la actividad comercial, se requería recaudar mayor evidencia material por el asegurado $^{118}$. Así, si bien la activación del amparo de lucro cesante tiene lugar en el momento en que la empresa sufre las pérdidas subsiguientes a la interrupción del negocio ${ }^{119}$, el asegurado no justificó el lapso de tiempo que tomó para hacer la declaración del siniestro.

Esta decisión de la Queen's Bench Division (Mercantile Court) coincide con la Sentencia de la Corte Suprema de Colombia en el sentido de determinar que el elemento necesario para la operación de la garantía de lucro cesante es la verificación de las pérdidas sufridas por el asegurado. De nuevo la Corte Suprema armoniza con el estado de derecho en las latitudes extranjeras donde estos debates se dieron hace decenios, lo cual no hace sino otorgar al país una justicia más moderna con estándares más técnicos respecto de las nociones de derecho de seguros.

116 Laker Vent Engineering Limited v Templeton Insurance Limited [2009] Court of Appeal (Civil Division) (Reino Unido), EWCA Civ 62, Judge: Aikens LJ.

117 "The words "... any cause, event or circumstance which has given or is likely to give rise to...", therefore refer to a state of affairs which can be objectively ascertained" parágrafo nro. 82 Laker Vent Engineering Limited v Templeton Insurance Limited [2009].

118 Parágrafo nro. 32, Loyaltrend Ltd v Creechurch Dedicated Ltd. [2010].

119 "But of course the trigger for business interruption loss is not the subsidence but the material damage" parágrafo nro. 32 . 


\section{BIBLIOGRAFIA}

\section{Doctrina}

Abravanel-Jolly, S. (2010) Deux contrats souscrits par le Syndicat et par la SCI. Garantie réclamée sur le seul fondement du contrat souscrit par le Syndicat. Revue générale du droit des assurances - 01/01/2010 - n² 2010-01 - page 88, RGDA201088.

Alzate Ossa, M. (2013). Los Incoterms, El Contrato de Seguro y la compraventa Internacional de mercaderías: La transferencia del dominio Y del riesgo en el contrato de Compraventa internacional y Los incoterms, y su relación con El interés asegurable y la cobertura En el contrato de seguro. Revista Principia Iuris nro. 19. Universidad Santo Tomás de Aquino.

Botero Morales, B. (2009), El Seguro de Lucro Cesante Forma Inglesa, Pérdida de Utilidad Bruta, Tesis de Grado, Pontificia Universidad Javeriana, Facultad De Economía.

Cárdenas, M. B. (2010). Los seguros en Colombia. Apuntes Contables, Universidad Externado (12).

Castela, C. (2013) Perte d'exploitation : réparation intégrale. L'actualité juridique propriété immobilière, 2013 p.757 Dalloz.

Chao-hung Chen, C. (2014) Measuring the Transplantation of English Commercial Law in a Small Jurisdiction: An Empirical Study of Singapore's Insurance Judgments between 1965 and 2012, Texas International Law Journal. 49, (3), 469-505. Research Collection School Of Law.

Cleary, N. (2015) Brokers' duties and business interruption insurance, Bloomsbury Professional, Professional Negligence, WestLaw.

Contreras Calderón, J. A. (2011) El precedente judicial en Colombia: Un análisis desde la teoría del derecho. Revista Facultad de Derecho y Ciencias Políticas. Vol. 41, No. 115 / p. 331-361.

Derruppé, J. (2000) L'indemnité d'assurance pour perte d'exploitation n'est pas un élément du fonds de commerce. Revue trimestrelle de droit commercial et economique, Dalloz. RTD Com. 2000 p.72.

Dugdale, T. (2207) Limitation periods and a "continuing" duty of care, Professional Negligence, Bloomsbury Professional, WestLaw.

Galán Barrera, D. (2003) La compraventa internacional de mercaderías y su integración en el ordenamiento jurídico colombiano. Criterio Jurídico Santiago de CaliColombia $\mathrm{N}^{\circ} 3$ pp. 7-33. 
Gómez Sánchez, C. A.; Martínez del Río Samper, N. (2012) El interés asegurable como un elemento esencial del contrato de seguro de daños. Revista Ibero Latinoamericana de Seguros, Bogotá (Colombia), 36(21): 13-36, enero-junio de 2012.

Gross earnings coverage and gross profits insurance, Glossary of Insurance \& Risk Management Terms, International Risk Management Institute, 2016, recuperado el 8 de noviembre de 2016 en: https://www.irmi.com/online/insurance-glossary/ terms/g/gross-profits-insurance.aspx

Henao, J. C. (2007) El Daño. Universidad Externado, Bogotá.

JurisClasseur Responsabilité civile et Assurances (2003). Fasc. 521 : Assurances Terrestres. Assurances relatives aux biens, Pertes d'exploitation.

Kullman, J.; Habib-Deloncle L. et al. (2016) Lamy Assurances, Lamyline, Assurances dommages, Assurances des biens de l'entreprise.

Landel, J. Red. (2016) Pertes d'exploitation, Titre 1, Chapitre 1, Dictionnaire permanente droit des assurances, ElNet.

López Medina, D. E. (2004) El derecho de los jueces. Legis, Universidad de los Andes, Bogotá.

Mayaux, L. (1995) Interruption de la prescription. Limitation à la police visée dans la demande. Revue générale du droit des assurances - 01/04/1995 - n 1995-2 page 345, RGDA1995345.

Moreno, D. G. (2016). Tendencias del lucro cesante en el régimen de responsabilidad extracontractual de Estado en el derecho colombiano a partir de la Constitución de 1991. Academia \& Derecho, (10), 157-184.

Narváez Bonnet, J. E. (2014) Régimen vigente de la garantía única en la contratación estatal en Colombia. Revista Ibero-Latinoamericana de Seguros, Bogotá (Colombia), 40(23): 79-130, enero-junio de 2014.

Piedelièvre, S. (2000) La perte d'exploitation n'entre pas dans l'assiette du nantissement d'un fonds de commerce. Recueil Dalloz 2000 p.390.

Prado Simons, A. M. (2014) Fundamentos del Seguro de Responsabilidad Civil. Revista Ibero-Latinoamericana de Seguros, Bogotá (Colombia), 41(23): 119-139, julio-diciembre de 2014.

Restrepo Rodríguez, T. (2011) El reembolso de los costos de prevención en el seguro de responsabilidad civil en el derecho inglés. Revista de Derecho Privado, n. ${ }^{\circ}$ 20, enero-junio de 2011, pp. 399 a 435. 
Rossi M. A. (1998) Business interruption insurance coverage issues to consider for claims presentation and policy placement or renewal. International Insurance Law Review, Int. I.L.R. 71WestLaw.

Roberts, H. (2011) Riley on Business Interruption Insurance, Thomson Reuters, Londres.

Superintendencia Financiera de Colombia, Concepto 2015083405-002 del 16 de octubre de 2015.

Tamayo Jaramillo, J. Ossa Gómez, D. (2015) La responsabilidad civil y los seguros en la construcción de inmuebles: una aproximación comparativa entre el derecho colombiano y francés. Revista Ibero-Latinoamericana de Seguros, Bogotá (Colombia), 43(24): 171-191, julio-diciembre de 2015.

Vadja, P. (2010) De la fête de club aux jeux olympiques... check-list de l'assurance d'un événement sportif. Jurisport, Dalloz, 2010, nº6, p.31.

\section{Cortes colombianas}

- Corte Constitucional

Sentencia C- 836 de 2001, MP. Rodrigo Escobar Gil.

Sentencia C385 de 2008, MP. Clara Inés Vargas Hernández.

- Corte Suprema de Justicia de Colombia

Sentencia del 07 de junio de 1977. Corte Suprema de Justicia, Sala de Casación Civil. Gaceta Judicial 2396. M.P. José María Esguerra Samper. Bogotá: 1977.

Sala Civil de la Corte Suprema de Justicia de veintiuno 21 de febrero de 2012, Rad. 00537-01, MP. William Namén Vargas

- Consejo de Estado de Colombia

Sentencia No. 28278 de la Sección Tercera del Consejo de Estado de febrero 12 de 2015, C. P. Carlos Alberto Zambrano.

- Laudos arbitrales

C.I. Avetex S.A. contra BBVA Seguros Colombia S.A. 5 de diciembre de 2008, Pdte. Pedro José Bautista Moller.

Colombiana de Incubación S.A.-Incubacol-contra Seguros Colpatria S.A. 31 de Marzo de 2.009, Pdte Antonio De Irisarri Restrepo. 


\section{Cortes francesas}

Cass. 1re civ., 17 nov. 1987: Resp. civ. et assur. 1988, comm. 370

Cass. 1re civ., 29 mars 1989: Juris-Data n 1989-001696

Cass. 1re civ., 28 oct. 1991 Resp. civ. et assur. 1992, comm. 206.

Cour de cassation (1re Ch. civ.), 21 mars 1995, n. 92-13286

Cass. 1re civ., 8 juill. 1997, $\mathrm{n}^{\circ} 95-17.069, \mathrm{n}^{\circ} 1319 \mathrm{P}$

Cass. 1re civ., 9 nov. 1999: Juris-Data n 1999-003917

Cass. 1re civ., 7 nov. 2000, ${ }^{\circ} 97-22.294, n^{\circ} 1644$

Cour de cas sation (2e Ch. civ.), 13 mars 2009, n. 09-11940

Cass. 2e civ., 7 oct. $2010, \mathrm{n}^{\circ} 09-70.264$

\section{Cortes estadounidenses}

Peloso v. Hartford Fire Insurance Co 56 N.J. 514 (1970) 267 A.2d 498, Supreme Court of New Jersey, Judge: Schettino J.

\section{Cortes inglesas}

Sugar Hut Group Ltd v AJ Insurance, Queen's Bench Division (Commercial Court) 20 October 2014 [2014] EWHC 3352 (Comm), Judge: Eder J.

Eurokey Recycling Ltd v Giles Insurance Brokers Ltd Queen's Bench Division (Commercial Court) [2014] EWHC 2989 (Comm) [2015] 2 All E.R. (Comm) 55 (QBD (Comm), Judge: Blair J.

Loyaltrend Ltd v Creechurch Dedicated Ltd Queen's Bench Division (Mercantile Court) 05 March 2010 [2010] EWHC 425 (Comm); [2010] Lloyd's Rep. I.R. 466, Judge: Mackie QC.

Laker Vent Engineering Limited v Templeton Insurance Limited [2009] Court of Appeal (Civil Division), EWCA Civ 62, Judge: Aikens LJ. 
